\title{
Seroprevalencia de HTLV1/2 en donantes de sangre, Boyacá - Colombia, 2011-2013
}

\author{
Seroprevalence 1/2 HTLV in blood donors in Boyacá - Colombia between 2011 and 2013
}

Mabel Idaliana Medina-Alfonso', Sandra Marina Forero-Pulido², Román Yesid Ramírez-Rueda³

\begin{abstract}
1 Bacterióloga, Especialista en Gerencia de Instituciones de Seguridad Social Hospitalaria. Profesional Universitario. Gobernación de Boyacá. Tunja, Colombia. e-mail: mabel.medina@boyaca.gov.co

2 Bacterióloga, Especialista en Gerencia Hospitalaria. Profesional contratista Secretaria de Salud de Boyacá. Tunja, Colombia. e-mail: safopu@gmail.com

3 Bacteriólogo y Laboratorista Clínico, Magister en Microbiología. Tunja, Colombia. e-mail: electrónica:royer94@gmail.com
\end{abstract}

\begin{abstract}
Resumen
Introducción: El virus linfotrópico humano de células T es un retrovirus, se encuentra asociado al riesgo de presentar dermatitis infecciosa, uveítis, polimiositis, artropatías, paraparesia espástica tropical, linfoma de células T del adulto y mieloma. Una de las vías de transmisión del HTLV 1/2 es la transfusión sanguínea de unidades que contienen el virus. Para evitar la transmisión de la infección por este retrovirus, el tamizaje en muestras de donantes de sangre ha sido obligatorio en muchos países y más recientemente en Colombia. Objetivo: Reportar la seroprevalencia de virus HTLV 1/ 2 en donantes de sangre de Boyacá-Colombia entre los años 2011 a 2013. Materiales y Métodos: Estudio descriptivo retrospectivo, en el que se estableció la seroprevalencia de HTLV 1/2 en 48.782 donantes de sangre captados en el departamento de Boyacá por tres bancos de sangre, utilizando la técnica quimioluminiscencia y como pruebas confirmatorias la técnica de InmunoBlot. Resultados: De los donantes tamizados, el 0,23\% (113/48.782) fueron serorreactivos (positivos en la prueba de quimioluminiscencia), el 0,16\% (78/48.782) fueron negativos, un 0,04\% (21/48.782) fueron indeterminados y el 0,03\% (14/48.782) fueron seropositivos por la técnica de InmunoBlot. Los donantes seropositivos correspondieron según el sexo a 0,016\% (8/48.782) mujeres y 0,012\% (6/48.782) a hombres. Conclusión: La prevalencia de HTLV $1 / 2$ fue de $0,03 \%$, similar a la de la mayoría de países que cuentan con reporte de esta determinación en donantes de sangre. Los datos generados en el estudio son los primeros reportados para Boyacá y aportan a la epidemiología del virus a nivel nacional.
\end{abstract}

Palabras clave: Virus 1 linfotrópico T humano; virus 2 linfotrópico T humano; seroprevalencia; bancos de sangre; transfusión sanguínea. (Fuente: DeCS, Bireme).

\begin{abstract}
Introduction: The Human T-cell lymphotropic virus is a retrovirus found to be associated with risks of infectious dermatitis, uveitis, polymyositis, arthropathies, tropical spastic paraparesis, myeloma and T-cell lymphoma. One of the means of transmission of HTLV $1 / 2$ is the transfusion of blood units contaminated by the virus. To prevent this kind of transmission, blood donor screening has recently become a standard in Colombia and in many other countries. Objective: To report the seroprevalence of HTLV 1/2 virus in blood donors from Boyacá between 2011 and 2013.
\end{abstract}


Materials and Methods: A retrospective descriptive study was performed, in which the seroprevalence of HTLV $1 / 2$ was established in 48,782 blood donors from three blood banks in the department of Boyacá by using both chemiluminescence and western blot techniques. Results: From the screened donors, 0.23\% (113 / 48,782) were seroreactive (chemiluminescence positive), 0.16\% (78 / 48,782) were negative, $0.04 \%(21 / 48,782)$ were undefined and $0.03 \%(14 / 48,782)$ were seropositive by western blot. Concerning gender, seropositive donors were $0.016 \%$ $(8 / 48,782)$ female and $0.012 \%$ (6 / 48,782) male. Conclusion: The prevalence of HTLV $1 / 2$ was $0.03 \%$ which is similar to what has been found in most of the countries. The data generated in this study is the first of this kind available for Boyacá and will likely contribute to the virus epidemiology at the national level.

Keywords: Human T-cell lymphotropic virus 1; human T-cell lymphotropic virus 2; seroprevalence; blood banks; blood transfusion. (Source: DeCS, Bireme).

\section{Introducción}

Los retrovirus pertenecen a la familia Retroviridae, son virus con envoltura que presentan un genoma de ARN monocatenario de polaridad positiva y se replican de manera inusual a través de una forma intermedia de ADN bicatenario. Estos virus son responsables de muchas enfermedades, incluyendo algunos cánceres y el SIDA. El virus linfotrópico humano de células $\mathrm{T}$ (HTLV) es un retrovirus que pertenece a la subfamilia Oncovirinae, del cual se conocen cuatro serotipos ${ }^{1}$.

El HTLV-1se conoce como el primer retrovirus oncógeno humano reportado por primera vez en 1980 , se encuentra principalmente asociado al riesgo de presentar dermatitis infecciosa, uveítis, polimiositis, artropatías y es de mayor importancia clínica en el desarrollo de enfermedades como la paraparesia espástica tropical (PET), el linfoma de células $\mathrm{T}$ del adulto (LTA) y el mieloma asociado a HTLV-1 (MAH) ${ }^{2}$. Se estima que la distribución de la infección por HTLV-1 en el mundo es de aproximadamente 10 a 20 millones de individuos infectados. Las principales regiones altamente endémicas son el sudoeste de Japón, África Subsahariana, América del Sur, el Caribe, y focos en Oriente Medio y Australo-Melanesia 3 .

El HTLV-2 fue aislado en 1982, siendo el segundo retrovirus linfotrópico aislado en diferentes tribus de amerindios, pigmeos y en usuarios de drogas intravenosas del mundo occidental.La patogenicidad de este virus ha sido asociada a síndromes neurológicos similares a la MAH/PET; aun cuando todavía no se dispone de evidencias suficientes para confirmar su rol etiológico en estas enfermedades ${ }^{4}$. HTLV-2 también se ha relacionado con el incremento en la incidencia de neumonía, bronquitis, tuberculosis, infecciones de vías urinarias y abscesos en piel y tejidos blandos. Otros estudios han concluido que la coinfección HTLV-2/HIV-1 no afecta independientemente el progreso de la enfermedad por HIV, no obstante, en pacientes con coinfección HTLV-2/HIV-1 que cursan con neuropatía sensorial, se ha establecido que la tasa de replicación viral de HTLV-2 es mayor 5 .

Las vías asociadas a la transmisión del HTLV 1 y 2 son la transmisión vertical (principalmente asociado a la lactancia materna), contacto sexual, empleo de jeringas compartidas en uso de drogas intravenosas y transfusión de componentes sanguíneos ${ }^{6}$. Las complicaciones más importantes en receptores de hemocomponentes son de orden neurológico y oncogénico, cuyo riesgo se potencializa con la transfusión de elementos celulares debido a que estos virus infectan linfocitos, por lo tanto su probabilidad de infección no es alta en productos extracelulares como plasma fresco congelado y crioprecipitado. La mayoría de portadores del virus HTLV-1 permanecen sanos y sólo desarrollan complicaciones hematológicas entre un 2 y 4\% ${ }^{7}$.

Dos de las principales vías de transmisión del HTLV-1/2 son la transfusión sanguínea y la reutilización de agujas de usuarios de drogas intravenosas que están infectados por el virus. Para evitar la transmisión de la infección por estos retrovirus, el tamizaje en muestras de donantes de sangre ha sido obligatorio en países como: Japón (1986), Estados Unidos e Islas 
Caribeñas Francesas (1989), Canadá y Francia (1990), Países Bajos del continente europeo y Suecia (1993), Dinamarca e Irán (1994), Costa Rica (2002), siendo este el primer país de América Latina en tener una cobertura de tamizaje para HTLV-1/2 al $100 \%{ }^{8}$. Algunas prevalencias reportadas para estos retrovirus en donantes de sangre en América varían entre 0,02\% (Costa Rica) y 1,59\% (Estados Unidos) 9 .

En Colombia a partir del año 2014 la prueba de tamizaje y confirmatoria de HTLV $1 / 2$ es obligatoria en bancos de sangre, no obstante con el fin de garantizar la seguridad transfusional, el departamento de Boyacá implementó el tamizaje y confirmación de HTLV I-II para donantes de sangre a partir del año 2011, por lo cual, es el interés de este estudio conocer retrospectivamente, la seroprevalencia en este grupo de población ${ }^{10}$.

\section{Materiales y métodos}

Estudio descriptivo retrospectivo, en el que se estableció la seroprevalencia de HTLV $1 / 2$ en 48.782 donantes de sangre captados en el departamento de Boyacá por los bancos de sangre: Hemocentro del Centro Oriente Colombiano (HCOC), Fundación Hematológica Colombia (FUHECO) y Cruz Roja Colombiana (CRC); durante los años 2011 a 2013 a través del sistema de información de hemovigilancia.

Para el tamizaje de HTLV-1/2, los bancos de sangre utilizaron la técnica quimioluminiscencia; para las pruebas confirmatorias, emplearon la técnica InmunoBlot, siguiendo los lineamientos establecidos en la Circular 0082 de 2011 emitida por el Instituto Nacional de Salud y el Ministerio de Salud y Protección Social.

Los datos de edad, sexo y resultados del tamizaje para HTLV-1/2 fueron generados por cada uno de los bancos de sangre, los resultados de la prueba confirmatoria para HTLV-1/2 para el año 2011 fueron reportados por el Laboratorio Departamental de Salud Pública de Boyacá y en los años 2012 a 2013 por los bancos de sangre incluidos en el estudio. Los participantes diligenciaron la declaración y consentimiento del donante establecida en la encuesta para selección de donante de sangre del Ministerio de Salud y Protección Social ${ }^{11 .}$.

Tomando como base la seroprevalencia del HTLV $1 / 2$ a partir de los datos emitidos por las instituciones incluidas en el estudio, se realizó análisis estadístico descriptivo a las variables en estudio. Se generó la distribución por sexo y edad con respecto a la serorreactividad (positivos en la prueba de tamizaje) y a la seropositividad (positivos en la prueba confirmatoria).

\section{Resultados}

Del total de los donantes tamizados, el 0,23\% (113/48.782) fueron serorreactivos (positivos en la prueba de quimioluminiscencia). El 0,16\% (78/48.782) negativos, un $0,04 \%$ (21/48.782) fueron indeterminados y el $0,03 \%(14 / 48.782)$ resultaron seropositivos por la técnica de InmunoBlot.

Durante el periodo estudiado se observa que en el año 2012 la seropositividad para HTLV 1/2 fue 2,6 veces más alta que en los años 2011 y 2013, como se observa en la gráfico 1.

Gráfico 1. Porcentaje de donantes seropositivos. Boyacá-Colombia, 2011-2013

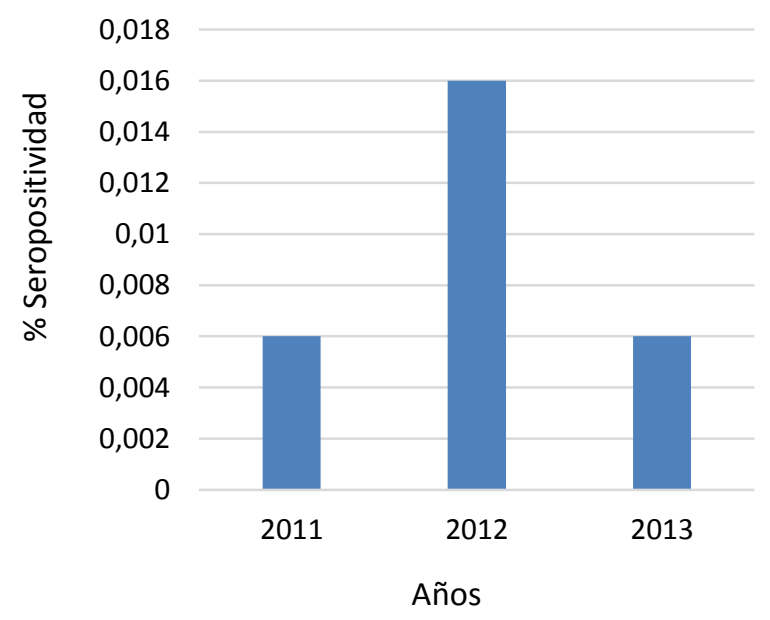


Para reportar la seropositividad por sexo, es importante tener en cuenta la frecuencia de donación de hombres con respecto a la de mujeres. Durante el periodo evaluado, la mayor frecuencia en donación por sexo fue para las mujeres con 25.353 unidades de sangre en comparación con los hombres, cuyas unidades recibidas en el periodo fueron 23.206. Los donantes seropositivos corresponden según el sexo a mujeres en un $0,016 \%(8 / 48.782)$ y a hombres en un $0,012 \%(6 / 48.782)$, distribuidos en rangos de edad. (Tabla 1 )

Tabla 1. Distribución por sexo y rangos de edad de donantes de sangre seropositivos para HTLV 1/2

\begin{tabular}{lcc}
\hline Rango edad & Masculino & Sexo \\
\hline $18-30$ & 1 & \\
$31-40$ & 3 & 0 \\
$41-50$ & 0 & 3 \\
$51-65$ & 2 & 2 \\
SD & 0 & 2 \\
Total & 6 & 1 \\
& & 8 \\
\hline
\end{tabular}

\section{Discusión}

La prevalencia confirmada (con resultado positivo en el InmunoBlot) correspondió al 0,03\% del total de los individuos tamizados y el $0,04 \%$ fueron indeterminados, es decir la cantidad de resultados indeterminados (21 donantes), es mayor que la cantidad de positivos (14 donantes). Los donantes con resultado indeterminado, no tienen certeza del reporte real de la prueba y no pueden ser incorporados como aptos para donar, quedando como donantes diferidos permanentes. Lo anterior motiva la posibilidad de considerar la PCR para HTLV 1/2 como una prueba confirmatoria eficaz, que traería múltiples beneficios para los donantes y para el banco de sangre.

La disminución de la positividad observada entre los resultados del InmunoBlod frente a los de PCR para HTLV 1/2, reportada en estudios individuales es franca, como ejemplos de este comportamiento tenemos estudios realizados en varios países alrededor del mundo, como Grecia con un $0,046 \%(24 / 51714)$ de indeterminados en la prueba $\mathrm{WB}$, y $0 \%$ con $\mathrm{PCR}^{12}$, en el Líbano en donde la prevalencia por WB fue de $0,06 \%$ y por PCR $0,03 \%{ }^{13}$, diferente a lo reportado en una investigación realizada en donantes de Venezuela, en donde 17 donantes fueron positivos por WB y el mismo número confirmado por PCR ${ }^{14}$.

Comparando el resultado de la prevalencia del presente trabajo con estudios provenientes de países en donde no se hace confirmación por PCR (sólo WB por duplicado), los valores son más altos, como por ejemplo en Mozambique (Maputo) con 0,89\% para HTLV-15. Argentina (Provincia de Santa Fe) con $0,1 \%{ }^{6}$, Arabia Saudita con $0,06^{16}$ y Colombia (Bogotá) con $0,07 \%{ }^{17}$. Por el contrario en Brasil (Estado de Maranhão) donde se hizo un seguimiento por siete años, se encontró una prevalencia más baja que fue del $0,02 \% 18$. Algunas prevalencias de zonas endémicas y no endémicas de Colombia como la reportada para el Valle del Cauca $(0,45 \%)$ en 1.997, subrayaban la importancia de tener en cuenta la detección de HTLV 1/2 en Colombia ${ }^{19}$.

Antes de la vigencia de la ley por la cual se hacía imperativa la aplicación de la prueba para detección de anticuerpos contra HTLV 1/2 en los bancos de sangre de Colombia, ya en muchos de ellos se había implantado la medida, es así que recientemente se presenta un reporte de un estudio retrospectivo que da a conocer la prevalencia del tamizaje (prueba de ELISA) en bancos de sangre de Bogotá e Ibagué, las cuales fueron $0,15 \%$ y $0,2 \%$ respectivamente, siendo dichas prevalencias ligeramente menores a la hallada en la fase de tamizaje en el presente estudio, que fue del $0,23 \%{ }^{20}$. Pocos estudios reportan resultados de sólo el tamizaje de HTLV $1 / 2$, sin embargo, la prevalencia de tamizaje para HTLV 1/2 en Malí en 2011 fue de 1,4\%, cifra que sobrepasa a la reportada en este estudio ${ }^{21}$. La importancia de las pruebas moleculares (PCR) en la confirmación de los resultados obtenidos en el tamizaje se evidencia en estudios que realizan esta prueba, como en el estudio hecho en Chile (Valdivia) en donde se reporta un $0,45 \%$ de positividad en el tamizaje para HTLV-1 (ELISA) y $0,24 \%$ en PCR 22 . 
El presente trabajo reporta los primeros datos epidemiológicos documentados sobre HTLV en donantes en Boyacá, a su vez estas cifras aportan a la epidemiología de HTLV 1/2 a nivel nacional, puesto que en Colombia se tiene poca información documentada con respecto a este tópico. Del mismo modo, se quiso resaltar la importancia de las pruebas moleculares como estándares de oro para confirmar la presencia del DNA viral. Teniendo en cuenta que un promedio de 16.260 unidades de sangre o sus componentes (según el periodo de estudio) pueden ser trasfundidas al año en Boyacá y que entre un $2 \%$ al $4 \%$ de los individuos que se contagian con HTLV pueden desarrollar complicaciones, la determinación del virus en unidades de sangre es una estrategia que hace de la transfusión de sangre en Colombia un procedimiento más seguro.

\section{Conflicto de intereses: Ninguno declarado por} autores.

\section{Referencias}

1. Dimmock N, Easton A, Leppard K. Introduction to modern virology. 6 ed. United States: Blackwell Publisher; 2007.

2. Okayama A. Natural history of human T-lymphotropic virus type 1 infection and inmune system imbalance. Inflamm Regen. 2010;30(2):103-8.

3. Gessain A, Cassar O. Epidemiological aspects and world distribution of HTLV-1 infection. Frontiers in Microbiology. 2012;3:1-23.

4. Cortés A, Beltrán M, Gallego G, Isaza L. Estudio prospectivo seroepidemiológico de infección por el virus linfotrópico humano I y II (HTLV-I/II) en donantes de sangre de áreas colombianas endémicas y no endémicas. Colom Med. 1999;30(1):19-25.

5. Roucoux D, Murphy E. The epidemiology and disease outcomes of human T-lymphotropic virus type II. AIDS Reviews. 2004;6:144-54.

6. Brun R, Astarloa L, Salomón H, Biglione M. Prevalencia de infección por HTLV-I/II en donantes de sangre de la provincia de Santa $\mathrm{Fe}$ Argentina. Medicina. 2004;64:125-8.

7. Rivero R. Tansmisión de infecciones virales por la transfusión de sangre. Rev Cubana Hematol Inmunol Hemoter. 2006;22:1-23.

8. García Z, Cortés X, Torres L, Araúz P, Pacheco E, Taylor L. Detección de anticuerpos contra los virus linfotrópicos de células T tipo I/II (HTLV I/II) como medida de seguridad sanguínea en donantes de sangre en Costa Rica, mayo del 2002 a diciembre del 2004. RCCM. 2006;27(1-2):1-18.

9. Glynn S, Kleinman S, Schreiber G, Busch M, Wright D, Smith J, et al. Trends in incidence and prevalence of major transfusion-transmissible viral infections in US blood donors, 1991 to 1996. AMA. 2000;284:1-7.

10. República de Colombia. Ministerio de Salud y Protección Social. Resolución No. 000437 Diario oficial. 2014:1-2.

11. República de Colombia. Ministerio de Salud. Guía para la selección de donantes de sangre en Colombia. Bogotá: Ministerio; 2012.

12. Zervou EK, Georgiadou S, Tzilianos M, Georgitsi P, Pournara V, Nousis S, et al. Human T-lymphotropic virus type I/II infections in volunteer blood donors from northern and western Greece: increased prevalence in one blood bank unit. Eur J Intern Med. 2004;15(7):42227.

13. Tamim H, Musharrafieh U, Ramia S, Almawi WY, Al-Jisr $\mathrm{T}$, Ayoub T, et al. Is seroprevalence of HTLV-I/II among blood donors in Lebanon relevant?. Am J Infect Control. 2004;32(4):220-3.

14. León G, Quirós AM, López JL, Hung M, Díaz AM, Goncalves J, et al. Seropositividad al virus linfotrópico de células T humanas tipos I y II en donantes del Banco Municipal de Sangre de Caracas y factores de riesgo asociados. Rev Panam Salud Publica. 2003;13:2-3.

15. Gudo ES, Abreu CM, Mussá T, Augusto AdR, Otsuki K, Chambo E, et al. Serologic and molecular typing of human T-lymphotropic virus among blood donors in Maputo city, Mozambique. Transfusion. 2009;49(6):1146-50.

16. Fawaz NA, Tamim H, Almawi WY. Low prevalence of antibodies to human T-lymphotropic virus-I/II among blood donors in eastern Saudi Arabia. Am J Infect Control. 2005;33(3):189-91.

17. Martínez-Nieto O, Rangel-Espinosa N, Morales-Reyes OL. Seroprevalencia de anticuerpos para virus linfotrópicos humanos (HTLV I/II) en donantes de sangre de una Clínica de Bogotá, Colombia. 1999-2004. Rev salud pública. 2007;9(2):253-61.

18. De Castro GM, Nascimento MSB, De Oliveira RAS, Dos Santos AC, De Souza Galvão C, Da Silva MACN. Seroprevalence of HTLV-1/2 among blood donors in the state of Maranhão, Brazil. Rev Bras Hematol Hemoter. 2014;36(1):50-3.

19. Cortés A, Beltrán M, Gallego G, Isaza L. Estudio prospectivo seroepidemiológico de infección por el virus linfotrópico humano I y II (HTLV - I/II) en donantes de sangre de áreas colombianas endémicas y no endémicas. Colombia Med. 1999;30(1):19-25.

20. Cruz H, Moreno JE, Restrepo M, Fonseca A. Seroprevalencia de tamizaje frente a virus linfotropico de células T (HTLV) y factores asociados a coinfecciòn en donantes voluntarios de sangre de Colombia. Salud Uninorte. 2014;30(2):95-103.

21. Diarra AB, Kouriba B, Guindo A, Maiga AI, Diabaté DT, Douyon I, et al. Prevalence of HTLV-I virus in blood donors and transfusion in Mali: Implications for blood safety. Transfusion Clinique et Biologique. 2014;21(3):139-42.

22. Chandía L, Sotomayor C, Ordenes S, Salas P, Navarrete M, Lopez M, et al. Seroprevalence of human T-cell lymphotropic virus type 1 and 2 in blood donors from the regional hospital of Valdivia, Chile. Med Microbiol Immun. 2010;199(4):341-4. 